\title{
Field experiment on effect of butaphosphan and cyanocobalamin complex on the immunity and stress of olive flounder at low temperature
}

\author{
Seung Min Kim ${ }^{1}$, Da Won Lee ${ }^{2}$, You Jeong Kim³ ${ }^{3}$ Lyu Jin Jun ${ }^{4}$, Hyun Kyung Park ${ }^{4}$, Ye Ji Kim , \\ You Yong Jeong ${ }^{3}$, Sung Ho Lee ${ }^{3}$, Mun Gyeong Kwon², Joon Bum Jeong, ${ }^{4, *}$ \\ ${ }^{1}$ Mokpo Regional Office, National Fishery Products Quality Management, Mokpo 58746, Korea \\ ${ }^{2}$ Aquatic Life Disease Control Division, National Fishery Products Quality Management, Busan 49111, Korea \\ ${ }^{3}$ Central Research Institute, Woogen B\&G, Hwaseong 18629, Korea \\ ${ }^{4}$ Department of Aquatic Biomedical Science, Jeju National University, Jeju 63243, Korea
}

\begin{abstract}
In this study, a fish metabolic accelerator (a combination of butaphosphan and cyanocobalamin [BPC]) was injected into the muscle of the olive flounder, Paralichthys olivaceus, to investigate its effect on immunity and stress in fish maintained at low temperatures. A single dose of BPC was injected (100 mg/kg body weight) into the olive flounder, and its immunity and stress were observed after one and two weeks. Immunity tests revealed the presence of lysozyme (LZM), nitroblue tetrazolium (NBT), myeloperoxidase (MPO), anti-protease (AP), glutathione peroxidase (GPx), and total immunoglobulin (TIg). BPC injection was found to increase immunity activity compared to the control group. In particular, there was significantly high GPx activity. There was similarly high activity for MPO and GPx in the first week following the injection, followed by significant differences between the BPC-injected and control groups in the second week. There was a reduced low water-temperature stress response in the BPC-injected fish, as evidenced by the cortisol and glucose levels of the control and BPC groups. Lower levels were also observed in the BPC group than the control group during the second week. Cortisol levels were significantly lower in the BPC group than the control group. Histological examinations were conducted in the first and second weeks after the intramuscular injection of the recommended BPC dose to confirm the safety of BPC in aquaculture. There were no abnormalities observed in any tissue samples. This study confirms that the injection of BPC is safe even when used in a culture situation. BPC helps relieve stress and improves non-specific immune responses (innate immunity) in the olive flounder.
\end{abstract}

Keywords: Butaphosphan, Cyanocobalamin, Immunity, Olive flounder, Stress

Received: Mar 9, 2021 Revised: Mar 26, 2021 Accepted: Mar 26, 2021

${ }^{*}$ Corresponding author: Joon Bum Jeong

Department of Aquatic Biomedical Science, Jeju National University, Jeju 63243, Korea

Tel: +82-64-754-3426, Fax: +82-64-756-3473, E-mail: jeongjb@jejunu.ac.kr

This is an Open Access article distributed under the terms of the Creative Commons Attribution Non-Commercial License (http://creativecommons.org/licenses/by$\mathrm{nc} / 4.0 /$ ) which permits unrestricted non-commercial use, distribution, and reproduction in any medium, provided the original work is properly cited.

Copyright $\odot 2021$ The Korean Society of Fisheries and Aquatic Science 


\section{Introduction}

Butaphosphan is a derivative of phosphoric acid, comprising water-soluble and colorless crystals of $\mathrm{H}_{2} \mathrm{PHO}_{3}$ (Fig. 1). It is a dibasic acid containing tetrahedral $\left[\mathrm{PHO}_{3}\right]^{2}$. Although not clearly proven, butaphosphan supplies phosphoric acid, which is the main component of adenosine triphosphate (ATP). Butophosphan activates metabolism in animals and improves muscle activity (EMEA, 2000; Rolling et al., 2010). In addition, it lowers the concentration of cortisol to reduce the stress of metabolic reactions and increases insulin levels; as such, it is able to improve intracellular glucose movement (Deniz et al., 2009).

Vitamin $B_{12}$ is water soluble; the term refers to various compounds that act as coenzymes in the human or animal body and the corresponding converted coenzymes. By promoting energy metabolism, it is possible to restore energy and reduce the accumulation of metabolites and the toxicity of butaphosphan (Cho, 2016).

Butaphosphan and cyanocobalamin mixture (BPC) are complex drugs used to improve animal health (Pereira et al., 2013a, b). BPC is known to reduce aggressive behavior in piglets by lowering cortisol levels in livestock (Van der Staay et al., 2007). After injecting BPC, cows showed improved postpartum metabolic ketosis and milk production (Fürll et al., 2010). BPC has also been reported to assist recovery from surgical procedures (Fürll et al., 2006; Fúrll et al., 2010). It has been reported that the side effects after surgery are alleviated by administering BPC in dogs, as it supports liver function and pancreatic enzyme activity. It also increases the hematopoietic process to suppress the elevation in the liver, a side effect of dexamethasone (Deniz et al., 2009). In terms of the efficacy of BPC in fish, there have only been a few studies conducted at the laboratory level owing to a lack of knowledge compared to other livestock. Seo

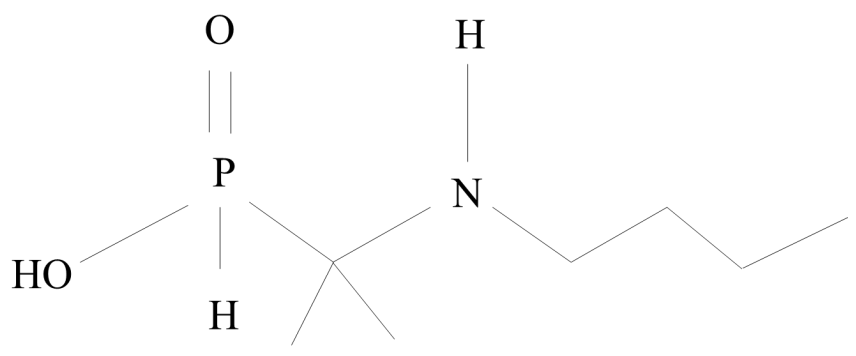

Fig. 1. Chemical structure of 1-(butylamino)-1methylethyl-phosphonic acid in BPC (active component). BPC, butaphosphan and cyanocobalamin. et al. (2020) reported a case in which reduced cortisol levels and partial improvements in the immune parameters were observed after an injection of BPC in the olive flounder. Mechesso et al. (2019) reported that in the high-density culture of the olive flounder, BPC suppressed damage to the immune system and tissues. In addition, Kim et al. (2020) confirmed that BPC induces a lower stress response from water-temperature changes by lowering cortisol levels in the olive flounder. It has also been reported that BPC improves egg production and reproductive function in female Nile tilapia (Alkobaby, 2008).

Various studies have confirmed the usefulness of BPC in livestock and fish. In the current study, we aimed to determine whether the recommended doses of BPC were appropriate for the olive flounder (Paralichthys olivaceus). We specifically investigated the improvement in the immunity and stress response of the flounders to low water temperature during winter, as it is a major problem in domestic fish farms. Histological examinations were also conducted to determine the toxicity of the recommended BPC dose. This experiment was conducted on the olive flounder as it is one of the most important aquaculture species in Asian countries.

\section{Methods}

\section{Fish}

About 5,000 olive flounders were used as experimental fish at the culture site located in Haengwon-ri, Gujwa-eup, Jeju (Fig. 2). The fish were divided into a control group (average weight: $216.6 \pm 55 \mathrm{~g}$ ) and a BPC group (average weight: $243 \pm 23 \mathrm{~g}$ ). Each experimental tank $(10 \mathrm{~m} \times 10 \mathrm{~m})$ consisted of a flow system with a flow rate of $12-18$ rotations/h. During the experiment, the average water temperature was $15.2 \pm 0.23{ }^{\circ} \mathrm{C}$. This temperature is typically low for the habitat of the olive flounder, as the optimum temperature for this species is $21^{\circ} \mathrm{C}$. The salinity of seawater used in the culture was 31.3\%-33.9\%, and the dissolved oxygen (DO) was in the range of 5.8-6.5 mg/L. The fish were supplied a commercial olive flounder feed (Suhyup) and fed twice daily (8:00 am and 4:00 pm) for two weeks throughout the experimental period.

\section{Test material}

The BPC complex used in the experiment was a metabolism accelerator (butaphosphan $100 \mathrm{mg}$ and cyanocobalamin 0.05 $\mathrm{mg} / \mathrm{mL}$ ) licensed as a pharmaceutical product for fisheries by the National Institute of Fisheries Science (NIFS, 2018). The 


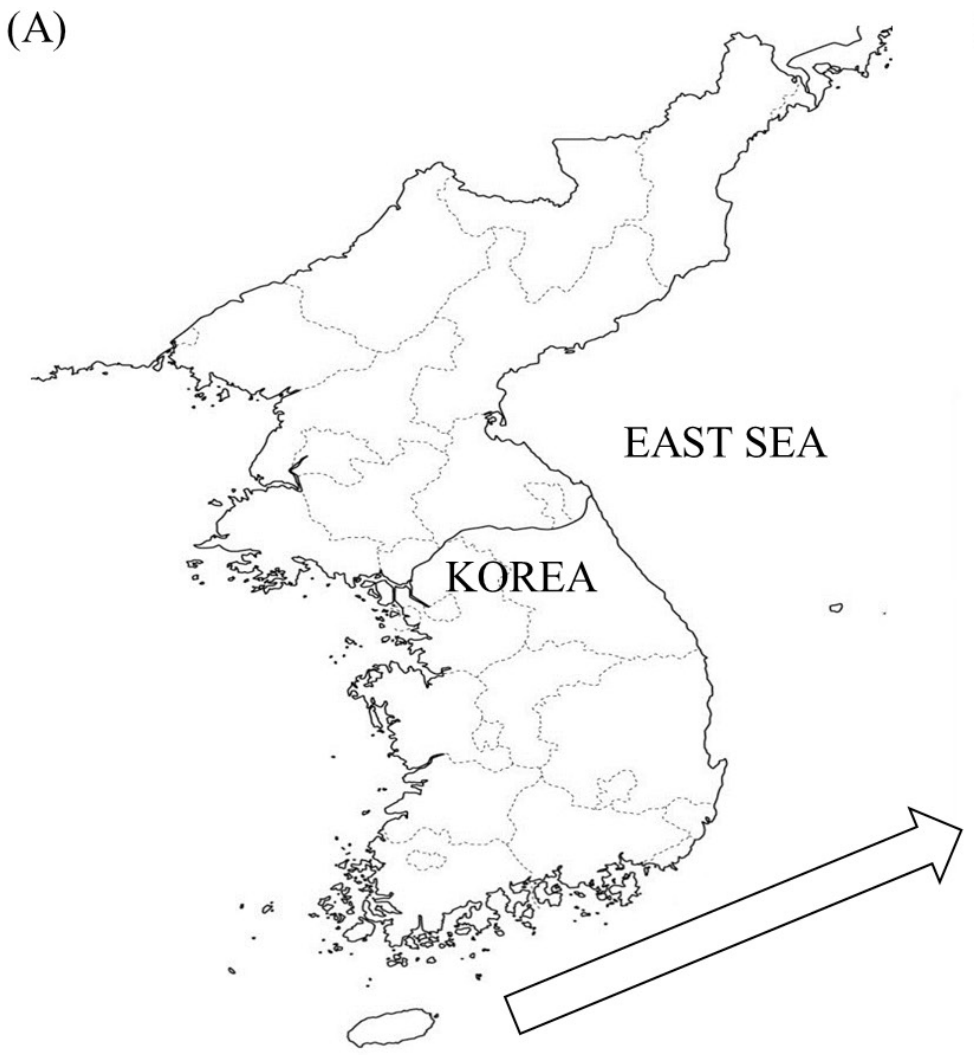

(B)

Jeju Island

Fig. 2. Location of study area. (A) Jeju Island, (B) Jeju Island map with topography and location of the Haengwon-ri.

guidelines recommend injection into the abdominal cavity and muscles. In this experiment, we administered intramuscular injections due to the safety of the olive flounder. This meant that only one intramuscular injection was required as per the recommended dose and use ( $0.5 \mathrm{~mL} / \mathrm{kg}$ of fish body weight). The control group was injected with a similar amount of physiological saline to meet the same conditions (intramuscular injection) as that of the experimental group.

\section{Sample collection}

Five fish were randomly selected for blood collection and each subsequent experiment. Fish were anesthetized with a 2-phenoxyethanol solution (100 ppm), and blood was collected near the caudal fin using a heparin-treated syringe. The collected whole blood was used for nitroblue tetrazolium (NBT) analysis. After analysis, the plasma was separated by centrifugation $(4,424 \times \mathrm{g}$ for $10 \mathrm{~min})$, and an immune response and stress analysis was conducted. Blood that was not treated with heparin for serum separation was also collected using a syringe. The serum was separated by centrifugation $(4,424 \times \mathrm{g}$ for $10 \mathrm{~min})$, and used in immunoassays. All samples were collected from the fish within $3 \mathrm{~min}$, and a recovery time of $5 \mathrm{~min}$ was provided for each individual as per the guidance in Weber et al. (2009), which reports that this timeframe is required to prevent longterm physiological stress caused by anesthetics.

\section{BPC safety and immunity test}

The safety test involved randomized item observations including natatorial speed, feeding behavior, internal and external observation, and mortality rate, following the intramuscular BPC injection. Each observation of an item in the control and BPC groups was recorded for two weeks, and immunological parameters were evaluated at weeks one and two. Lysozyme (LZM) in serum was evaluated following the methodology of Yeh et al. (2008). Serum glutathione peroxidase (GPx) activity was determined using a GPx activity kit and following the manufacturer's instructions (BioVision, Milpitase, CA, USA). Total immunoglobulin (TIg) analysis in plasma was analyzed using 
the method reported by Siwicki \& Anderson (1993). Myeloperoxidase (MPO) activity in the serum was analyzed as described by Kumari \& Sahoo (2005). NBT in the blood was analyzed using the method described by Kumari \& Sahoo (2005). The anti-protease (AP) in the serum was analyzed following the procedure described by Ellis (1990).

\section{Lyosozyme analysis}

Serum LZM activity was determined using a turbidometric assay (Yeh et al., 2008) with lyophilized Micrococcus lysodeikticus (M. lysodeikticus) cells (Sigma-Aldrich, St. Louis, MO, USA). Briefly, wells of an ELISA plate were filled with $10 \mu \mathrm{L}$ of individual serum, mixed with $200 \mu \mathrm{L}$ of a M. lysodeikticus suspension (0.2 $\mathrm{mg} / \mathrm{mL}$ in $0.05 \mathrm{M}$ sodium phosphate buffer [ $\mathrm{pH} 6.2])$, and maintained at $25^{\circ} \mathrm{C}$. The absorbance was measured at $530 \mathrm{~nm}$ using a plate reader after 1 and $6 \mathrm{~min}$. LZM activity (1 unit) was defined as a decrease in sample absorbance by $0.001 / \mathrm{min}$.

\section{Nitroblue tetrazolium analysis}

Activation of serum macrophage was determined by measuring neutrophil oxidative-radical generation using the method described by Kumari \& Sahoo (2005). Samples of whole blood (50 $\mu \mathrm{L})$ and NBT solution ( $0.2 \%)$ were placed in a glass test tube. Next, $1 \mathrm{~mL}$ of dimethyl formamide was added to reduce the generated formazan, and samples were centrifuged at $2,000 \times \mathrm{g}$ for $5 \mathrm{~min}$. The extent of NBT reduction was determined by quantifying the absorbance of the supernatant at $540 \mathrm{~nm}$ (Genesys 10UA, Genesys, Daly City, CA, USA). Dimethyl formamide was used as the blank.

\section{Myeloperoxidase analysis}

Serum MPO activation was determined using the method described by Kumari \& Sahoo (2005). Each well of a 96-well plate was filled with $80 \mu \mathrm{L}$ of Hanks' Balanced Salt Solution and 20 $\mu \mathrm{L}$ of serum, to which $20 \mathrm{mM}$ of $3,3^{\prime}, 5,5^{\prime}$-tetramethybenzidine (TMB) and $5 \mathrm{mM} \mathrm{H}_{2} \mathrm{O}_{2}$ were added. The samples were allowed to react for $2 \mathrm{~min}$. Then, $15 \mu \mathrm{L}$ of $4 \mathrm{M} \mathrm{H}_{2} \mathrm{SO}_{4}$ solution was added prior to measuring optical density at $450 \mathrm{~nm}$ using a microplate reader (Thermo Fisher Scientific, Waltham, MA, USA).

\section{Anti-protease analysis}

Serum AP activation was determined using the method described by Ellis (1990). Serum samples $(20 \mu \mathrm{L})$ were mixed with $20 \mu \mathrm{L}$ of trypsin solution and incubated at $22^{\circ} \mathrm{C}$ for $10 \mathrm{~min}$. Then, $200 \mu \mathrm{L}$ of phosphate buffer (0.1 M, pH 7.0) and $250 \mu \mathrm{L}$ of azocasein (2\%) were added to each sample, and the mixtures were reacted at $22^{\circ} \mathrm{C}$ for $30 \mathrm{~min}$. The samples were centrifuged at $6,000 \times \mathrm{g}$, and $100-\mu \mathrm{L}$ aliquots of supernatants were placed in a 96-well plate together with $100 \mu \mathrm{L}$ of $\mathrm{NaOH}(1 \mathrm{~N})$. The optical density was measured at $430 \mathrm{~nm}$.

\section{Glutathione peroxidase analysis}

Serum GPx activation was measured according to the manufacturer's instructions (BioVision). Briefly, serum samples were placed in a 96-well plate, and NADH, glutathione, and glutathione reductase were added. The optical density of the solution was measured at $340 \mathrm{~nm}$ using a microplate reader.

\section{Total immunoglobulin analysis}

TIg was determined in serum using the method described by Siwicki \& Anderson (1993). Immunoglobulins were precipitated with $12 \%$ polyethylene glycol (Sigma-Aldrich) solution and quantified using a Bradford protein assay (Sigma C-690).

\section{Stress test}

The cortisol concentration in the plasma was analyzed using a cortisol enzyme immunoassay (EIA) kit (BioVision), after inducing an antigen and antibody reaction. The glucose concentration in the plasma was analyzed using an automatic biochemical analyzer (Catalyst One, IDEXX, Westbrook, ME, USA). Each analysis was performed in triplicate.

\section{Statistical analysis}

SPSS (Ver. 21, IBM, Armonk, NY, USA) was used to conduct $t$-tests and determine any statistically significant differences. Differences were considered statistically significant at $p<0.05$.

\section{Histological analysis}

The gills, muscles, kidneys, liver, spleen, and intestine (injected area) were extracted from sampled fish. Samples were fixed in Bouin's solution for $24 \mathrm{~h}$ and dehydrated using 70\% ethanol. Tissues were embedded in paraffin (Leica EG 1150HC, Leica, Wetzlar, Germany), using an embedder (Leica Jung 820, Leica) and sliced using a microtome. The sliced tissues were mounted on glass slides, dried, and stained with hematoxylin and eosin. The samples were analyzed using optical microscopy (Zeiss LT60, Carl Zeiss Microscopy, Jena,Germany) to observe abnormal histology potentially caused by BPC. 


\section{Results}

\section{BPC safety and immunity test}

No abnormal behavior was observed in the safety test when comparing the BPC with the control group. No abnormal findings were observed in feed intake, natatorial speed, and inner and external observations during the test period (data not shown). The mortality rate was $0.24 \%$ in the control group and $0.2 \%$ in the BPC group (data not shown); thus, the latter had a lower mortality rate than the control during the test period. Immunological analysis revealed higher activity in the BPC group than the control group in all test items in the first week, with significantly higher GPx activity (Table 1). During the second week, there was higher activity in the BPC group than the control group across all test items, similar to the first week; in particular, MPO and GPx showed significantly higher activity (Table 1).

\section{Stress test}

The observed stress response in olive flounder revealed that there was no significant difference in the cortisol levels between the control and BPC groups in the first week, while there were significantly lower values in the BPC group in the second week (Fig. 3). There were no differences in glucose levels observed in the first week; however, a lower value was obtained in the BPC group compared to the control group in the second week (Fig. 3).

\section{Histological analysis}

A similar histological morphology was observed in the BPC group in weeks one and two when compared to the control

Table 1. Control with BPC immunological test results at weeks one and two

\begin{tabular}{|c|c|c|c|c|c|c|c|}
\hline & Groups & $\begin{array}{l}\text { LZM } \\
\text { (units/mL) }\end{array}$ & $\begin{array}{l}\text { NBT } \\
\text { (absorbance) }\end{array}$ & $\begin{array}{l}\text { MPO } \\
\text { (absorbance) }\end{array}$ & $\begin{array}{l}\text { AP } \\
\text { (\%, inhibition) }\end{array}$ & $\begin{array}{l}\text { GPx } \\
(\mathrm{mU} / \mathrm{mL})\end{array}$ & $\begin{array}{l}\text { Tlg } \\
(\mathrm{mg} / \mathrm{ml})\end{array}$ \\
\hline \multirow[t]{2}{*}{1 week } & Control & $23.3 \pm 3$ & $0.38 \pm 0.08$ & $2.5 \pm 0.16$ & $73.3 \pm 3.05$ & $23.2 \pm 0.23$ & $34.3 \pm 2.26$ \\
\hline & $\mathrm{BPC}$ & $24.5 \pm 3.53$ & $0.41 \pm 0.02$ & $2.85 \pm 0.2$ & $75 \pm 2.64$ & $33.4 \pm 0.33^{*}$ & $35.9 \pm 0.66$ \\
\hline \multirow[t]{2}{*}{2 weeks } & Control & $22 \pm 14.5$ & $0.78 \pm 0.07$ & $2.43 \pm 0.05$ & $82.3 \pm 1.52$ & $38 \pm 1.95$ & $30.4 \pm 3.69$ \\
\hline & $\mathrm{BPC}$ & $22.3 \pm 3.51$ & $0.78 \pm 0.06$ & $2.83 \pm 0.16^{*}$ & $83.3 \pm 2.51$ & $41.3 \pm 4.82^{*}$ & $31.2 \pm 2.52$ \\
\hline
\end{tabular}

* Significant difference between control group and BPC group based on the $t$-test $(p<0.05)$.

BPC, butaphosphan and cyanocobalamin; LZM, lysozyme; NBT, nitro-blue tetrazolium; MPO, myeloperoxidase; AP, anti-protease; GPx, glutathione peroxidase; Tlg, total immunoglobulin.

(A)

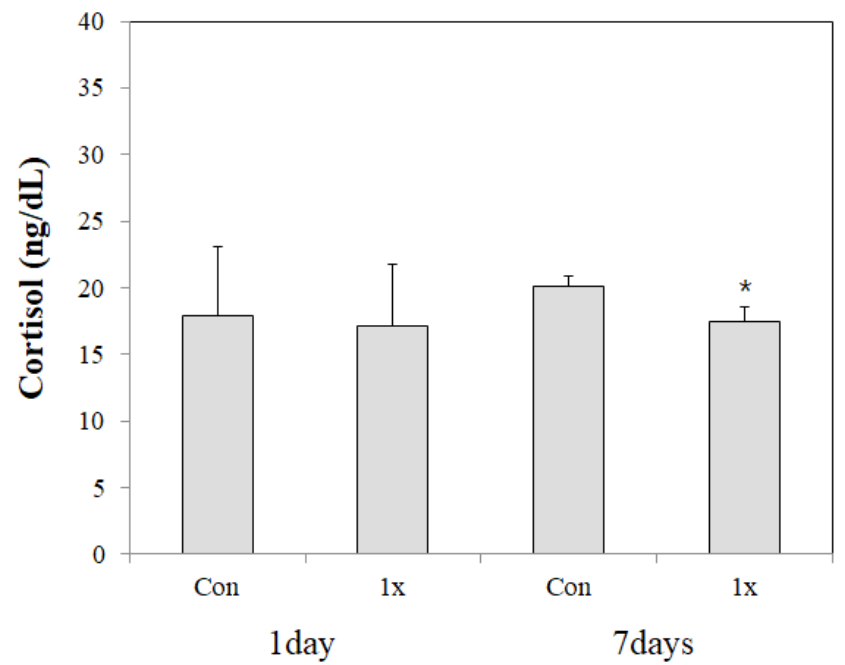

(B)

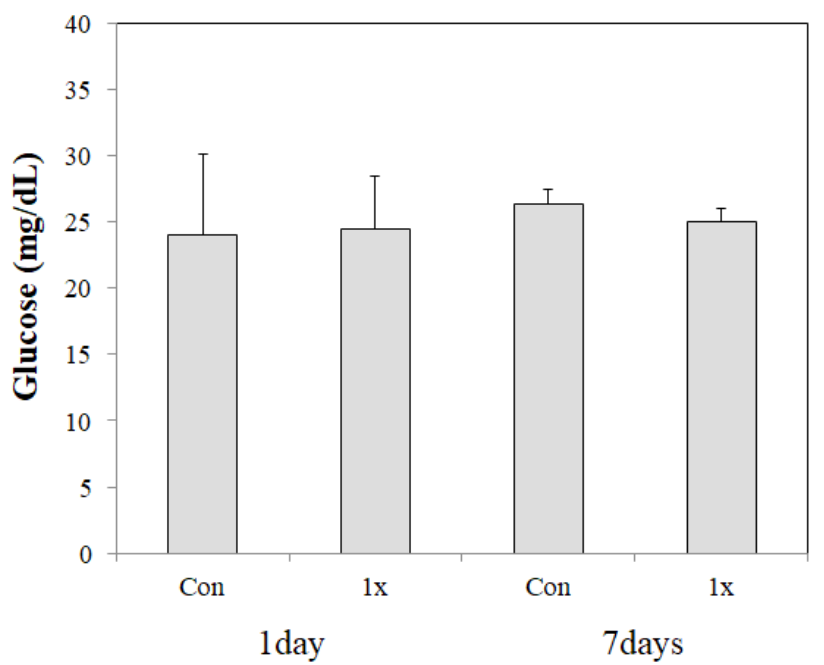

Fig. 3. Changes in cortisol and glucose concentrations at weeks one and two in the control and BPC groups. BPC, butaphosphan and cyanocobalamin. 
group. The gill filament and gill lamellae exhibited a uniform arrangement, and changes, such as gill bleeding, congestion, and necrosis of epithelial cells, induced by toxic substances were not observed in the BPC group (Fig. 4A). Abnormalities were not observed in the muscle area surrounding the initial injection site in the BPC group, and infiltration or bleeding of muscle fibers and inflammatory cells were not found in the muscle area (Fig. 4B). In addition, the liver contained normal connective tissue, hepatocytes, sinusoids, and exocrine pancreas cover in both groups. Kidney abnormalities did not occur in the hematopoietic tissue, renal corpuscles, collecting tubes, or endothelial cells
(Fig. 4C, 4D). The intestinal microvilli, intestinal villi, and submucosa were also normal in both groups (Fig. 4E). The spleen tissue contained a consistent number of red blood cells in both groups. There was no increase in the number of leukocytes in the BPC group (Fig. 4F). As such, there was no inflammation or side effects caused by BPC injection.

\section{Discussion}

$\mathrm{BPC}$ is a metabolic accelerator and medicine in fishery, which has been widely used to enhance immunity and reduce stress

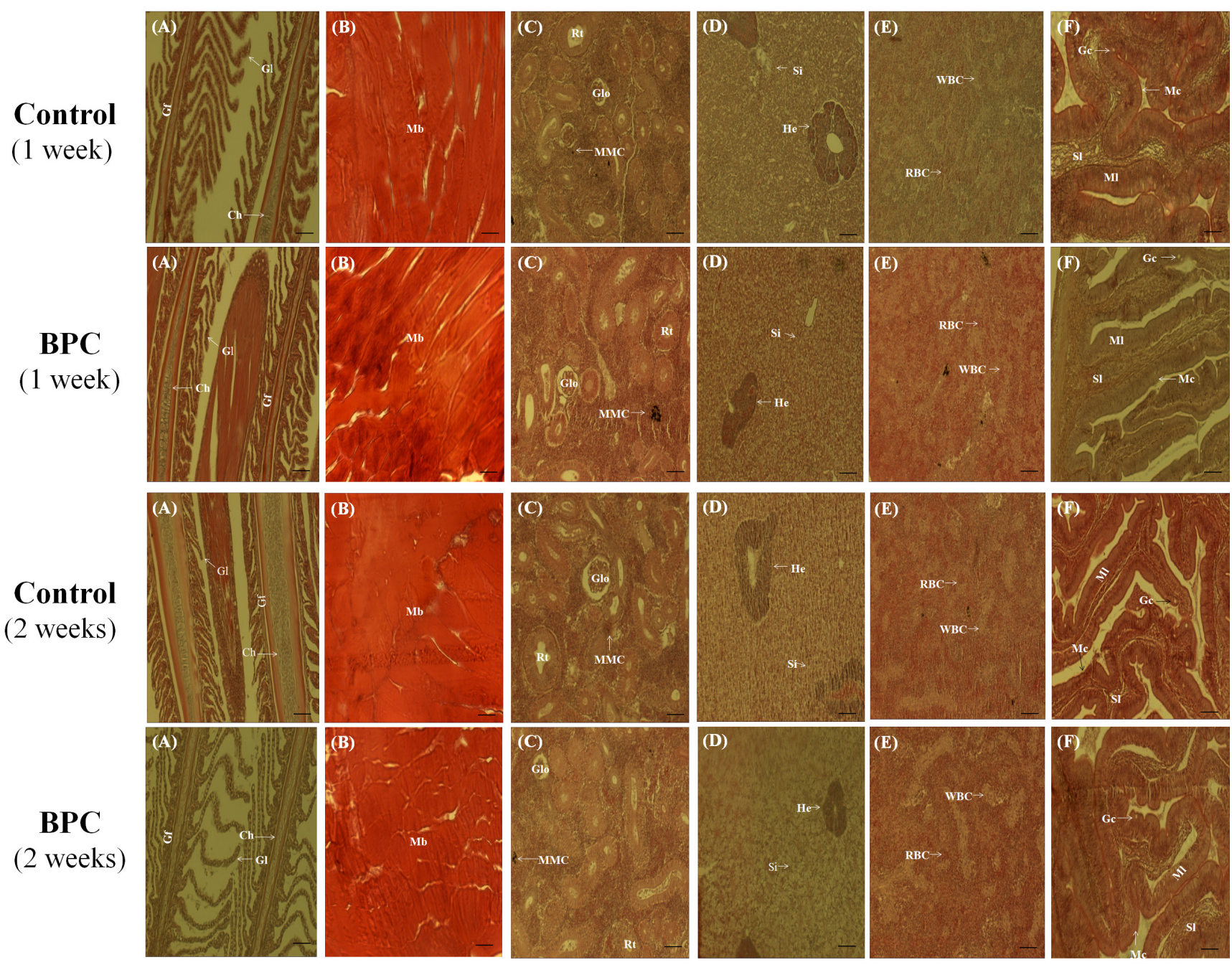

Fig. 4. Histological results of the (A) gill, (B) muscle, (C) kidney, (D) liver, (E) spleen and (F) intestine after BPC injection for weeks one and two. H\&E (scale bar = $20 \mu \mathrm{m}$ ). Ch, chondrocyte; Gc, goblet cell; Gf, gill filament; Gl, gill lamella; Glo, glomerulus; He, hepatocyte; Mb, muscle bundle; Mc, mucous cell; Ml, mucosal layer; MMC, melanomacrophage; Pc, pillar cell; RBC, red blood cell; Rt, renal tubule; Si, sinusoid; Sl, submucosal layer; WBC, white blood cell-enriched region; BPC, butaphosphan and cyanocobalamin. 
in the domestic olive flounder. However, the efficacy evaluation results from a laboratory-level feeding experiment are available, with no data available on farm conditions (Mechesso et al., 2019; Seo et al., 2020). In this study, we evaluated the efficacy of BPC against immune stress in a low-temperature olive flounder farm using the recommended guidelines. In addition, histological analysis was used to confirm BPC toxicity at the recommended dose.

Butaphosphan and vitamins are classified as safe substances (EMA, 2014; MFDS, 2013). Kim et al. (2020) found that general safety tests (i.e., feeding, behavior, branchial movement, internal and external features, mortality) showed no negative repercussions from the intramuscular injection of the recommended dose of BPC in olive flounder at the optimum water temperature. The results from this study were consistent with previous findings, with the exception of mortality rate. In Kim et al. (2020), an increased mortality rate was not recorded during the test period. Conversely, this experiment recorded some mortality; this discrepancy may be owing to variations in experimental conditions as there were differences between the laboratory test conditions and aquaculture site conditions (e.g., water temperature and the number of fish). It is also inferred that BPC administration did not cause mortality, as there was a slightly higher mortality rate in the control group.

The olive flounder can physiologically adapt to a wide range of water temperature. When the environmental water temperature is lower than their preferred temperature, their immunity decreases due to a reduction in metabolic rate (Kim \& Jung, 2014). As the activity of digestive enzymes and the metabolic rate of fish decrease at low water temperatures $\left(10^{\circ} \mathrm{C}-15^{\circ} \mathrm{C}\right)$ compared to the proper water temperature $\left(20^{\circ} \mathrm{C}-25^{\circ} \mathrm{C}\right)$, a decrease in immunity is observed (Fauconneau et al., 1983). The results of this study highlighted the immunological efficacy of $\mathrm{BPC}$ in the olive flounder at low water temperatures.

It has been reported that an increase in the non-specific immune response in fish may reduce mortality and improve the production of healthy fish (Chen \& Ainsworth, 1992; Kajita et al., 1992). Non-specific defense in fish is considered the first line of defense against pathogen infection; the ability to resist pathogens may be strengthened by the activation of the innate immune system (Siwicki et al., 1994). LZM is an enzyme exhibiting antibacterial activity against a wide spectrum of bacterial species, combined with the antibacterial activity of the hydrolyzing $\beta-1,4$ bond of peptidoglycan, which is a component of the bacterial cell wall (Grinde, 1989). NBT increases the levels of reactive oxygen species (ROS) by hydrolyzing bacterial and viral parasites that have invaded the body; this immune cell accounts for $60 \%-70 \%$ of the immune cells that make up the primary defense through sterilization and phagocytosis. MPO is a peroxidase present in neutrophils, basophils, and eosinophils, which converts hydrogen peroxide into hypochlorous acid (HClO) to kill pathogens (Palić et al., 2005). An increase in MPO activity in vivo elevates the immune response by amplifying the antibacterial effect against pathogens. In this study, we measured LZM, NBT, and MPO activity following BPC injection. BPC was found to enhance the non-specific immune response (innate immunity) in olive flounder. These results show a consistent trend alongside the results of a previous study wherein experiments were conducted at the appropriate water temperature (Kim et al., 2020). However, this experiment revealed differences in activity over time (for the first and second weeks) in LZM, NBT, and MPO. Kim et al. (2020) did not appear greater than the results. This discrepancy may be related to the different breeding conditions involved in the experiments (i.e., water temperature, olive flounder size, number of flounder, and laboratory versus field conditions). GPx activity is a representative antioxidant enzyme known to prevent cellular damage to ROS (Lope et al., 2001), and AP activity is known to reduce tissue damage (Park et al., 2016). TIg has been reported to improve immunity by increasing acidophilic granulocytes (Picchietti et al., 2007). We observed higher GPx, AP, and TIg activity in the BPC-injected group than in the control group. These results were similar to the immune response results for humoral and cell-mediated immunity; in mice and cows, the immune response increased after injecting butaphosphan into mice, resulting in increased tissue-regeneration ability (Flasshoff, 1974; Hasi et al., 2004). The intramuscular injection of BPC activated the immune system. The results from this study are in agreement with those reported by Kim et al. (2020). BPC was effectively delivered to the body of the olive flounder.

$\mathrm{BPC}$ is an amino acid phosphonic acid derivative containing phosphorus. Its exact mechanism involved has not yet been identified (EMEA, 1999). It has been reported that BPC can accelerate ATP production by providing inorganic phosphate that helps oxidative phosphorylation (Hasi et al., 2005a, 2005b). Cortisol, one of the stress indicators for fish, is an indicator of stress as its levels in blood increase when fish are stressed (Kang et al., 2007). The increase in glucose, which occurs after elevated cortisol concentrations, is a phenomenon that uses ATP within fish to combat stress (Kang et al., 2007). The stress test results 
after the first week were similar between the control and BPC groups, and differences between the two groups occurred in the second week. In the BPC group, the cortisol and glucose levels were similar to those in the first week, while in the control group, the cortisol and glucose concentrations were higher than the first week. These results were consistent with those of Seo et al. (2020), who found that the cortisol concentration after the intramuscular injection of saline (control) and BPC in olive flounder maintained at high densities resulted in a decrease in cortisol concentration in the BPC-treated group compared to the saline-treated group. Following the intramuscular injection of saline and BPC, the concentrations of cortisol and glucose changed with water temperature. These findings are consistent with the results of decreasing cortisol and glucose concentrations in the BPC-treated group compared to the saline-treated group (Kim et al., 2020). Currently, the exact mechanism underlying the relationship between BPC and stress has not been elucidated; the results show that certain values were observed in the BPC group compared to the control group. The stress-reduction effect in olive flounder growing at low water temperature and the increase in cortisol and glucose levels in the control group suggests that the levels increased to cope with the stress caused by low water temperature.

The establishment of allowable residual standards for domestic veterinary drugs aligns with international standards, which are set by a combination of toxicity and persistence assessments. However, butaphosphan and vitamins are classified as safe substances and are exempt from residual and toxicity assessments (EMA, 2014; MFDS, 2013). Previous studies demonstrate that when $\mathrm{BPC}$ is injected one, three, or six times in olive flounders, the aspartate aminotransferase (AST) level increases significantly following the sixth injection. The study also determined liver toxicity; however, there were no toxic effects on the liver following one to three injections of BPC (Seo et al., 2020). Histological examination demonstrated that one, two, and four BPC injections in olive flounders did not change the normal histology in the tested groups (Kim et al., 2020). In the culture experiment at the laboratory level, there was no toxicity caused by the recommended dose, while in culture situations, different results have been obtained. Therefore, histological evaluation was used to determine the toxicity at the recommended dose; the same histological characteristics were observed in the BPC and control groups, and safety was confirmed.

This study provides the first piece of experimental evidence for the use of BPC in olive flounder at low water temperatures.
Taken together, BPC may be used to improve immunity and provide stress relief in the olive flounder. Further studies evaluating the effects of optimum and high temperatures of water are required. Furthermore, it is necessary to study the long-term effects of BPC on fish growth.

\section{Conclusions}

The results from this study indicated that BPC could effectively reduces stress levels by decreasing the production of cortisol and glucose. BPC improved the wellbeing of olive flounders, particularly when administered before or during stressful situations.

\section{Competing interests}

No potential conflict of interest relevant to this article was reported.

\section{Funding sources}

This work was supported by a grant from the National Fishery Products Quality Management Service.

\section{Acknowledgements}

This work was supported by a grant from the National Fishery Products Quality Management Service and the research grant of Jeju National University in 2020.

\section{Availability of data and materials}

All datasets generated and/or analyzed during the current study are available from the corresponding author on a reasonable request.

\section{Ethics approval and consent to participate}

This article does not require IRB/IACUC approval because there are no human and animal participants.

\section{ORCID}

Seung Min Kim

https://orcid.org/0000-0002-7124-5895

Joon Bum Jeong

https://orcid.org/0000-0002-0544-4968

\section{References}

Alkobaby AI. Effects of maternal injection with organic phosphorus and vitamin B12 on reproductive performance and newly hatched offspring of Nile tilapia (Oreochromis niloti- 
cus). In: Proceedings of the 8th International Symposium on Tilapia in Aquaculture; 2008; Cairo, Egypt. p. 375-86.

Chen D, Ainsworth AJ. Glucan administration potentiates immune defense mechanism of channel catfish, Ictalurus punatatus Rafinesque. J Fish Dis. 1992;15:295-304.

Cho Y. Pharmaceutical composition for animal. Korea patent 10-2016-0088486. 2016 Jul 26.

Deniz A, Spiecker-Hauser U, Rhagen M. Efficacy of a butafosfan and vitamin $\mathrm{B} 12$ combination $\left(\mathrm{Catosal}^{\circledR}\right)$ on biochemical and hematological blood parameters in dogs treated with dexamethason. Int J Appl Res Vet Med. 2009;7:116-29.

Ellis AE. Serum anti-protease in fish. In: Stolen JS, Fletcher TC, Anderson DP, Roberson WB, Van Muiswinkel WB, editors. Techniques in fish immunology. Fair Haven, NJ: SOS Publication; 1990. p. 95-9.

EMEA [European Agency for the Evaluation of Medicinal Products]. Committee for Veterinary Medicinal Products: barium selenate. London: EMEA; 1999. Report No.: EMEA/MRL/580/99-FINAL.

EMEA [European Agency for the Evaluation of Medicinal Products]. Committee for Veterinary Medicinal Products: butafosfan. London: EMEA: 2000. Report No.: EMEA/ MRL/734/00-FINAL.

EMA [European Medicines Agency]. European Public MRL assessment report (EPMAR): butafosfan (all mammalian food producing species). Amsterdam: EMA; 2014. Report No.: EMA/CVMP/335153/2013.

Fauconneau B, Choubert G, Blanc D, Breque J, Luquet P. Influence of environmental temperature on flow rate of foodstuffs through the gastrointestinal tract of rainbow trout. Aquaculture. 1983;34:27-39.

Flasshoff FH. Clinical and chemical blood serum investigations in cattle and treatment studies with ornithine-aspartate product HMV 20 and with catosal for the reduction of fertility and health disorders [Ph.D. dissertation]. Hannover: Tierarztliche Hochschule Hannover; 1974.

Fürll M, Deniz A, Westphal B, Illing C, Constable PD. Effect of multiple intravenous injections of butaphosphan and cyanocobalamin on the metabolism of periparturient dairy cows. J Dairy Sci. 2010;93:4155-64.

Fürll M, Wittek T, Gegenbach S, Schmidt B. Effects of preoperative application of butafosfan and cyanocobalamin on reconvalescence, clinico-chemical parameters, and antioxidative metabolism and postoperative abormasal emptying in cows with abomasal dislocation. Tierarztl Prax.
2006;34:351-6.

Grinde B. Lysozyme from rainbow trout, Salmo gairdneri Richardson, as an antibacterial against fish pathogens. J Fish Dis. 1989;12:92-104.

Hasi S, Jiang J, Zhu B. Studies on Anti-heat stress effects and mechanisms of compound butafosfon solution. Acta Vet Zootech Sinic. 2005b;36:1334.

Hasi SR, Du X, Zhu B, Jiang J. Studies on effects of compound butaphosphan solution on endurance capability and energy metabolism in mice. Acta Vet Zootech Sinic. 2004;35:290-4.

Hasi SR, Jiang J, Du X, Zhu B. Anti-cold stress effects and mechanisms of compound butaphosphan solution. Prog Vet Med. 2005a;26:59-62.

Kang DY, Kang HW, Kim GH, Jo KC, Kim HC. Effect of cold shock on the physiological responses of the cultured mullet, Mugil haematocheilus in winter. Korean J Fish Aquat Sci. 2007;40:226-33.

Kajita Y, Sakai M, Kobayashi M, Kawaushi H. Enhancement of non-specific cytotoxic activity of leucocytes in rainbow trout Oncorhynchus mykiss injected with growth homone. Fish Shellfish Immunol. 1992;2:155-7.

Kang SJ, Kwon HC, Kim DJ, Kim MH, Kim Y, Son YC, et al. Fish physiology. Paju: Bioscience; 2007.

Kim JU, Jung SJ. cDNA microarray analysis of viral hemorrhagic septicemia infected olive flounder, Paralichthys olivacus: immune gene expression at different water temperature. J Fish Pathol. 2014;27:1-9.

Kim SM, Kim YJ, Lee DW, Jun LJ, Jeong JB, Park HK, et al. Effects of butaphosphan and cyanocobalamin mixture on immunity and stress in olive flounder, Paralichthys olivaceus. Fish Aquat Sci. 2020;23:26.

Kumari J, Sahoo PK. Effects of cyclophosphamide on the immune system and disease resistance of Asian catfish, Clarias batrachus. Fish Shellfish Immunol. 2005;19:307-16.

Lopes PA, Pinheiro T, Santos MC, Luz DA, Mathias MDL, Collares-Pereira MJ, et al. Response of antioxidant enzymes in freshwater fish populations (Leuciscus alburnoides complex) to inorganic pollutants exposure. Sci Total Environ. 2001;280:153-63.

Mechesso AF, Kim YG, Park SC. Effects of butaphosphan and cyanocobalamin combination on plasma immune and biochemical parameters of olive flounder (Paralichthys olivaceus) subjected to crowding stress. Aquacult Res. 2019;50:1611-7.

NIFS [National Institute of Fisheries Sciences]. Aquatic med- 
icine catalogue [Internet]. 2018 [cited 2019 Jan 4]. http:// www.nifs.go.kr/adms/search/goodsList.ad

Palić D, Andreasen CB, Menzel BW, Roth JA. A rapid direct assay to measure degranulation of primary granules in neutrophils from kidney of fathead minnow (Pimephales promelas Rafinesque, 1820). Fish Shellfish Immunol. 2005;19:217-27.

Park JY, Choi JE, Cha SI, Bae NC, Chae PH, Lee JY, et al. Prevalence of alpha1-antitrypsin genotypes in Koreans. Tuberc Respir Dis. 2016;50:229-35.

Pereira RA, Siveira PAS, Montagner P, Schneider A, Schmitt E, Rabassa VR, et al. Effect of butaphosphan and cyanocobalmin on postpartum metabolism and milk production in dairy cows. J Anim Biosci. 2003a;7:1143-7.

Pereira RA, Fensterseifer S, Barcelos VB, Martins CF, Schneider A, Schmitt E, et al. Metabolic parameters and dry matter intake of ewes treated with butaphosphan and cyanocobalamin in the early postpartum period. Small Rumin Res. 2013b;114:140-5.

Picchietti S, Mazzini M, Taddei AR, Renna R, Fausto AM, Mulero V, et al. Effects of administration of probiotic strains on GALT of larval gilthead seabream: immunohistochemical and ultrastructural studies. Fish Shellfish Immunol. 2007;22:57-67.

Rollin E, Berghaus RD, Rapnicki P, Godden SM, Overton MW. The effect of injectable butaphosphan and cyanocobalamin on postpartum serum $\beta$-hydroxybutyrate, calcium, and phosphorus concentrations in dairy cattle. J Dairy Sci. 2010;93:978-87.

Seo JS, Lee JH, Park JJ, Choi JS, Bae JS, Lee CW, et al. Biochemical and stress-attenuating effects of butaphosphan-cyanocobalamin combination drug in olive flounder Paralichthys olivaceus. Fish Sci. 2020;86:375-84.

Siwick i AK, Anderson DP. Nonspecific defense mechanisms assay in fish: II. potential killing activity of neutrophils and macrophages, lysozyme activity in serum and organs and total immunoglobulin (Ig) level in serum. In: Disease diagnosis and prevention methods. Olsztyn, Poland; 1993. Project No.: FAO-project GCP/INT/JPA.

Siwicki AK, Anderson DP, Rumsey GL. Dietary intake of immuostimulants by rainbow trout affects non-specific immunity and protection against furunculosis. Vet Immunol Immunopathol. 1994;41:125-39.

Van der Staay FJ, Groot JDE, Van Reenen CG, Hoving-Bolink AH, Schuurman T, Schmidt BH. Effects of butafosphan on salivary cortisol and behavioral response to social stress in piglets. Vet Pharmacol Therapeut. 2007;30:410-6.

Weber RA, Peleteiro JB, García Martín LO, Aldegunde M. The efficacy of 2-phenoxyethanol, metomidate, clove oil and MS-222 as anesthetic agents in the Senegalese sole (Solea senegalensis Kaup 1858). Aquaculture. 2009;288:147-50.

Yeh SP, Chang CA, Chang CY, Liu CH, Cheng W. Dietary sodium alginate administration affects fingerling growth and resistance to Streptococcus sp. and iridovirus, and juvenile non-specific immune responses of the orange-spotted grouper. Fish Shellfish Immunol. 2008;25:19-27. 